\title{
Present and Future of the Chilean Electrical Grid
}

\author{
Fabián Díaz \\ Faculty of Engineering \\ University of Talca \\ Curicó, Chile \\ Marco Rivera Héctor Chávez
Faculty of Engineering Faculty of Engineeri \\ Patrick Wheeler \\ University of Talca University of Santiago) \\ Curicó, Chile \\ Santiago, Chile \\ fadiaz11@alumnos.utalca.cl \\ marcoriv@utalca.cl \\ hector.chavez@usach.cl \\ Prical and Electronic Engineering \\ University of Nottingham \\ Nottingham, England \\ patrick.wheeler@nottingham.ac.uk.
}

\begin{abstract}
The technological development of Chile has lead to a major energy demand. This paper presents a description of the current reality of the Chilean electricity sector and its future. The vision and its advancements in Chile are matter of observation to develop a clearer picture for maintaining and increasing the penetration of renewables towards global decarbonification and climate change mitigation.

Index Terms-Renewable Energy, Electrical system, Distributed Generation, Smart Grid, Chile.
\end{abstract}

\section{INTRODUCTION}

$\mathbf{T}$ HE Chilean electricity sector is fully developed by private sector companies, carrying out the activities of generation, transmission and distribution of electrical energy from the generation plants to the final consumers, where the state acts as a regulatory, supervisory and subsidiary entity for energy companies [1].

Since the creation of the Ministry of Energy and the subsequent incorporation of the Energy Agenda, Chile has focused on improving its energy matrix in order to create a more flexible network that encourages the free market of the energy sector and is friendly to the environment, establishing as objectives the promotion of the implementation of NCRE (non-conventional renewable energy), development of energy efficiency, improvements in the interconnection and reliability of electrical systems. [2].

Currently, the implementation and investment policies in the development of a cleaner electric matrix has positioned Chile as one of the leading countries in the world in the use of NCRE, climbing from the seventh place in 2017 to the first place in the Climatescope 2018 ranking. [3].

The current Chilean electrical grid is unidirectional, where the electricity is generated from the different generating plants, being mainly composed of primary thermal and hydraulic energy sources and in a lower productive capacity by wind, solar, photovoltaic and biomass.

Chilean legislation, by means of Supreme Decree No. 237 establishes as a transmission to any line with substation with a voltage greater than $23[\mathrm{kV}]$ and with at least one section of line of length greater than $100[\mathrm{~km}]$, all lines of less voltage are consider distribution. This flow of electrical energy is represented in the scheme presented in Fig. 1.

This paper focuses on examining the main characteristics that define the current electrical situation in Chile, analyzing

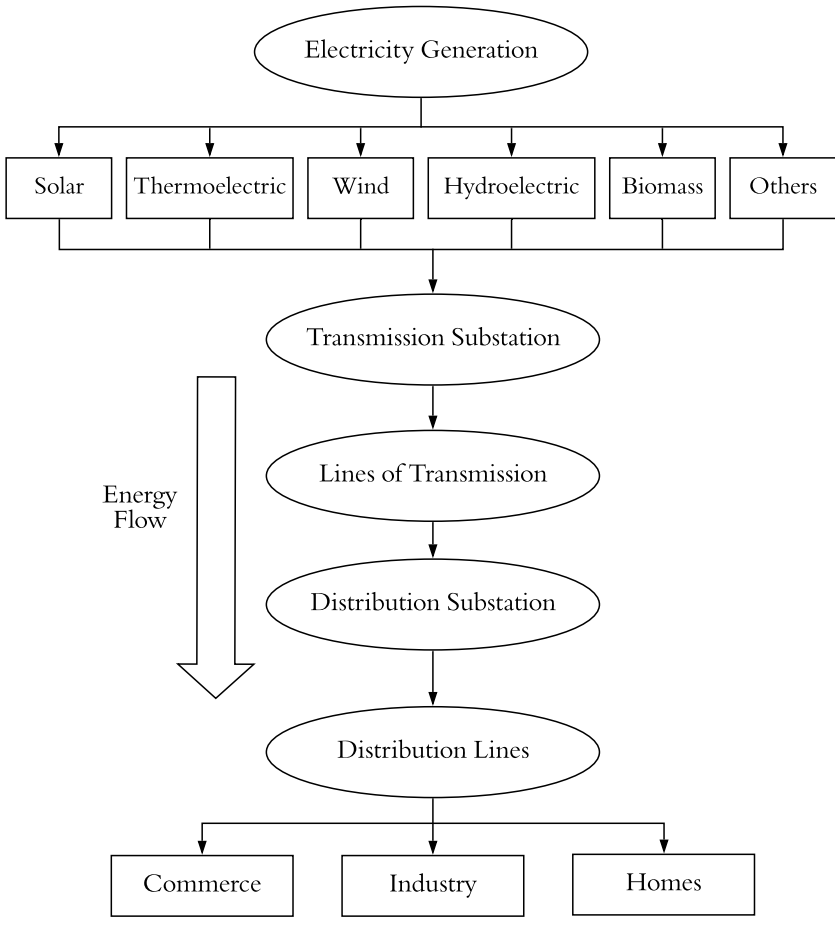

Fig. 1. General architecture of the current Chilean electrical grid.

the degree of interconnection and the scope of this system, together with the vision, laws and projects that define the present and future of the Chilean electrical grid.

\section{Characteristics of the CURrent Chilean ELECTRICAL GRID}

Currently, the Chilean electrical grid is made up of three interconnection systems, which connect the power plants and companies responsible for the generation, transmission and distribution of electricity. These systems are the SEN (National Electric System), SEA (Aysén Electric System) and SEM (Magallanes Electric System). Table I shows the installed generation capacity for each electrical system and its installed capacity based on renewable and non-renewable energies. Currently the SEN, SEA and SEM are composed of a set of electrical subsystems, which according to the current legislation are considered as medium systems. These are defined by the General Electric Services Law (LGSE), which stipulates 
TABLE I

ELECTRICITY GENERATION CAPACITY IN CHILE.

\begin{tabular}{|c|c|c|c|c|}
\hline Types of Energy & SEN [MW] & SEA [MW] & SEM [MW] & Total [MW] \\
\hline Renewable & 11424,34 & 26,42 & 2,55 & 11453,31 \\
\hline No Renewable & 12594,26 & 37,27 & 104,86 & 12736,39 \\
\hline Total & $\mathbf{2 4 0 1 8 , 6}$ & $\mathbf{6 3 , 6 9}$ & $\mathbf{1 0 7 , 4 1}$ & $\mathbf{2 4 1 8 9 , 7}$ \\
\hline
\end{tabular}

that medium-sized systems are all those with an installed capacity of $1.5[M W]$ to $200[M W]$ and that they also operate in areas away from the SEN. Likewise, this same law considers as isolated systems all those with an installed capacity of less than $1.5[M W]$, which usually operate in isolated areas or far from urban centers. Currently 109 of these systems are counted throughout the national territory [4].

There are two medium electrical systems for Easter Island and Los Lagos, however, these are considered isolated systems due to their geographical location and difficult access to interconnection, isolated electrical systems are not considered within the net generating capacity of Chilean electrical grid, it is also not considered the natural gas plant located in Salta (Argentina), interconnected to the SEN.

Chile's current electrical grid has $47 \%$ of its electricity production based on renewable energy and 53\% based on non-renewable energy. Renewable energies include nonconventional renewable energies or NCRE, which ensure that in the process of transforming their primary resource into electrical energy, it is not consumed or depleted, such as hydroelectric plants, although these by diverting river flows affect the environment where they are located. Among the new generation technologies based on hydraulic energy is the small hydro power plants, which consists of a small hydroelectric plant with an installed capacity of less than 20 [MW] (established in Law 20,257). Electricity production in Chile must have the generation, transmission and distribution companies coordinated for the dispatch of electricity at the lowest possible cost, a task that is carried out through the National Electrical Coordinator [5].

\section{A. National Electrical System (SEN)}

The National Electrical System (SEN) was born on November 21, 2017, interconnecting the most important old electrical systems in the country, SING (North Large Interconnected System) and SIC (Central Interconnected System), covering almost the entire national territory, from Arica to Chiloé.

The interconnection of the SING with the SIC is produced by the energizing and synchronizing the power lines in two specific areas of the country. The lines between Kapatur-Los Changos are interconnected by the Mejillones area. While the Copiapó area interconnects the lines between Los ChangosCumbres, Cumbres-Nueva Cardones and Nueva Cardones y Cardones [6]. This interconnection is achieved with the construction and commissioning of a $500[\mathrm{kV}]$ double circuit transmission line which is characterized by an approximate extension of $600[\mathrm{~km}]$, an approximate total of 1,355 towers next to 4 electrical substations, with two substations terminals
TABLE II

ELECTRICITY GENERATION CAPACITY OF THE SUBSYSTEMS THAT MAKE UP SEN.

\begin{tabular}{|c|c|c|c|}
\hline Types of Energy & SING [MW] & SIC $[M W]$ & SEN [MW] \\
\hline Renewables & $\mathbf{9 1 0 , 8 8}$ & $\mathbf{1 0 5 1 3 , 4 6}$ & $\mathbf{1 1 4 2 4 , 3 4}$ \\
\hline Hydraulic Reservoirs & 0,00 & 3354,64 & 3353,64 \\
\hline Hydraulic Pass & 0,00 & 2811,88 & 2811,88 \\
\hline Mini Hydraulic Pass & 17,08 & 497,49 & 514,57 \\
\hline Biomass & 0,00 & 507,08 & 507,08 \\
\hline Wind & 199,52 & 1543,57 & 1743,09 \\
\hline Solar & 654,58 & 1798,80 & 2453,38 \\
\hline Geothermal & 39,70 & 0,00 & 39,70 \\
\hline No Renewables & $\mathbf{5 0 0 8 , 6 8}$ & $\mathbf{7 5 8 5 , 5 8}$ & $\mathbf{1 2 5 9 4 , 2 6}$ \\
\hline Coal & 2796,45 & 2356,21 & 5152,66 \\
\hline Diesel Oil & 268,33 & 2694,17 & 2962,5 \\
\hline Natural Gas & 1943,90 & 2535,2 & 4479,1 \\
\hline Total & $\mathbf{5 9 1 9 , 5 6}$ & $\mathbf{1 8 0 9 9 , 0 4}$ & $\mathbf{2 4 0 1 8 , 6}$ \\
\hline
\end{tabular}

located in the Mejillones and Copiapó sectors. The first is located in Mejillones, this being a transformation substation (regulating the voltage levels for the electrical distribution), while the other corresponds to a compensation substation (which helps meet the energy demand) located in Diego de Almagro [7]. With the interconnection, the SING and SIC systems have now become subsystems of the SEN, allowing the use of the generational potential of the regions that cover both subsystems. The Table II shows the installed capacity of electricity generation, with the types of energy that characterize the subsystems that make up the SEN, which highlights the use of hydraulic energy and coal-based energy.

The interconnection allows a more competitive electricity market, achieving a better quality of service, reducing prices to end customers, a more secure and flexible matrix with ease of incorporation of NCRE.

The SEN caters to all locations between the Arica and Parinacota Region and the Los Lagos Region. It is a unique system in the world, with a total of $3,100[\mathrm{~km}]$ in length, 34,522.3 $[\mathrm{km}]$ of transmission lines from Arica to Chiloé with more than $99 \%$ coverage, coordination of 432 companies, with an installed power of 24,018.6 $[M W]$ and an annual production of 25,341.1 [GWh] of which 4,444.9 [GWh] have their origin in NCRE [8].

An important landmark within the SEN occurs on March 31, 2017, where the first geothermal plant in South America, Cerro Pabellón, began operations and is also the first largescale enthalpy geothermal plant built in the world at an altitude of 4,500[masl], is located in northern Chile in the commune of Ollagüe in the Atacama Desert, the Cerro Pabellón plant has an installed power of $48[M W]$ connected to the SEN supplying the network $340[G W h]$ per year [9].

\section{B. Aysén Electrical System (SEA)}

The SEA is the system that supplies the Aysén Region, in this system only EDELAYSEN (Empresa de Sociedad 
TABLE III

ELECTRICITY GENERATION CAPACITY OF THE SUBSYSTEMS THAT MAKE UP SEA.

\begin{tabular}{|c|c|c|c|c|}
\hline Types of Energy & $\begin{array}{c}\text { Aysén } \\
{[\mathrm{MW}]}\end{array}$ & $\begin{array}{c}\text { Gral. Carrera } \\
{[\mathrm{MW}]}\end{array}$ & $\begin{array}{c}\text { Palena } \\
{[\mathrm{MW}]}\end{array}$ & $\begin{array}{c}\text { SEA } \\
{[\mathrm{MW}]}\end{array}$ \\
\hline Renewables & $\mathbf{2 4 , 3 8}$ & $\mathbf{0 , 6 4}$ & $\mathbf{1 , 4 0}$ & $\mathbf{2 6 , 4 2}$ \\
\hline Mini Hydraulic Pass & 20,60 & 0,64 & 1,40 & 22,64 \\
\hline Wind & 3,78 & 0,00 & 0,00 & 3,78 \\
\hline No Renewables & $\mathbf{2 9 , 2 7}$ & $\mathbf{3 , 0 0}$ & $\mathbf{5 , 0 0}$ & $\mathbf{3 7 , 2 7}$ \\
\hline Diesel Oil & 29,27 & 3,00 & 5,00 & 37,27 \\
\hline Total & $\mathbf{5 3 , 6 5}$ & $\mathbf{3 , 6 4}$ & $\mathbf{6 , 4}$ & $\mathbf{6 3 , 6 9}$ \\
\hline
\end{tabular}

Austral de Electricidad S.A.) operates, occupying the work of generation, transmission and distribution of electrical energy.

As shown in Table III, SEA has an installed generation capacity of $63.69[M W]$ which represents $0.26 \%$ of the national installed capacity.

The SEA today has $41.48 \%$ of renewable energy in its generating matrix of which $5.93 \%$ is NCRE. EDELAYSEN currently produces $6.4[G W h]$ with wind units and 103.3 $[G W h]$ with hydraulic units for more than 35,500 users in the localities of Aysén and Coyhaique managing to produce more than $40 \%$ of its electricity with renewable energy sources [10].

\section{Magallanes Electrical System (SEM)}

The geographical location of the Magallanes Region has conditioned the configuration of its current electrical system, giving the condition of being a system with difficult access to interconnection to the other electrical systems of the country. Besides its territorial extension and its geographical irregularity, make implementing a single electrical system something very difficult to achieve due to the impossibility of interconnection between its main towns, which has been chosen to have electrical systems isolated from each other [11].

The SEM is the system responsible for supplying the Magallanes Region. This is composed of four independent subsystems, Punta Arenas System, Puerto Natales System, Porvenir System and Puerto Williams System.

Only the company EDELMAG (Empresa Eléctrica de Magallanes $S A$ ) operates in the Magallanes electrical system, the total installed capacity of this system is $107.41[M W]$, representing $0.44 \%$ of the generation capacity of the country, being a system in which $97.63 \%$ of its electricity supply is of thermal origin and only $2.37 \%$ of wind origin (Cabo Negro Wind Farm in Punta Arenas). In Table IV you can see in detail the installed power of each of the subsystems that creates the Magallanes electrical system.

\section{Easter Island Electrical System}

The present system has its origins between 1968 and 1969, where a NASA project was developed with the aim of enabling an alternative landing field for space shuttles. The Easter Island electrical system is a minor electrical system and only supplies
TABLE IV

ELECTRICITY GENERATION CAPACITY OF THE SUBSYSTEMS THAT MAKE UP SEM.

\begin{tabular}{|c|c|c|c|c|c|}
\hline Types of Energy & $\begin{array}{c}\text { Porvenir } \\
{[\mathrm{MW}]}\end{array}$ & $\begin{array}{c}\text { P. Natales } \\
{[\mathrm{MW}]}\end{array}$ & $\begin{array}{c}\text { P. Williams } \\
{[\mathrm{MW}]}\end{array}$ & $\begin{array}{c}\text { Pta. Arena } \\
{[\mathrm{MW}]}\end{array}$ & $\begin{array}{c}\text { SEM } \\
{[\mathrm{MW}]}\end{array}$ \\
\hline Renewables & $\mathbf{0 , 0 0}$ & $\mathbf{0 , 0 0}$ & $\mathbf{0 , 0 0}$ & $\mathbf{2 , 5 5}$ & $\mathbf{2 , 5 5}$ \\
\hline Wind & 0,00 & 0,00 & 0,00 & 2,55 & 2,55 \\
\hline No Renewables & $\mathbf{8 , 0 6}$ & $\mathbf{1 3 , 5 1}$ & $\mathbf{2 , 3 8}$ & $\mathbf{8 0 , 9 1}$ & $\mathbf{1 0 4 , 8 6}$ \\
\hline Diesel Oil & 3,06 & 4,24 & 2,38 & 6,41 & 16,09 \\
\hline Natural Gas & 5,00 & 9,27 & 0,00 & 74,50 & 88,77 \\
\hline Total & $\mathbf{8 , 0 6}$ & $\mathbf{1 3 , 5 1}$ & $\mathbf{2 , 3 8}$ & $\mathbf{8 3 , 4 6}$ & $\mathbf{1 0 7 , 4 1}$ \\
\hline
\end{tabular}

TABLE V

ELECTRICITY GENERATION CAPACITY OF EASTER ISLAND ELECTRICAL SYSTEM.

\begin{tabular}{|c|c|}
\hline Types of Energy & Easter Island Electrical System [MW] \\
\hline Renewables & $\mathbf{0 , 1}$ \\
\hline Solar & 0,1 \\
\hline No Renewables & $\mathbf{4 , 3}$ \\
\hline Diesel Oil & 4,3 \\
\hline Total & $\mathbf{4 , 4}$ \\
\hline
\end{tabular}

the electrical requirements of the island. It belongs to SASIPA (Sociedad Agrícola y Servicios Isla de Pascua SpA.), depends economically on the Ministry of Economy [12]. The Easter Island electrical system consists only of the Mataveri power plant. This system until 2018 only had one generation node, which consisted of five diesel generating units.

In November 2018, thanks to the Acciona company, the first photovoltaic generation plant on Easter Island, the Tama te Ra'a plant, consisting of 400 solar panels that constitute a total of $100[\mathrm{~kW}]$ [13], achieving with this bring renewable energy to a place as far away from the Chilean coast as Easter Island. Table $\mathrm{V}$ shows the installed power and the type of energy that are currently implemented in the electrical system of the island.

\section{E. Los Lagos Electrical System}

Los Lagos electrical system is a smaller system and supplies the towns of Hornopirén and Cochamó. This system is made up of the companies SAGESA (Sociedad Austral de Generación y Energía S.A.) and Electric Company Cuchildeo (of Energy of Patagonia and Aysén, EPA S.A.).

The installed capacity of this electrical system is composed of $10.24 \%$ by electricity obtained from energies from mini hydraulic pass-through plants, and $89.76 \%$ by energies from generator-based systems in diesel oil. Table VI shows the net installed generation capacity for the Los Lagos electrical system.

\section{F. Natural Gas-Fired Central Salta, Argentina}

The Salta thermoelectric power plant, located in Campo Santo province of Salta, in northwestern Argentina, is a combined cycle natural gas plant (with a system of two thermodynamic cycles, one with a water steam turbine and a gas turbine). It has a capacity of $643[M W]$ and supplies 
TABLE VI

ELECTRICITY GENERATION CAPACITY OF THE SUBSYSTEMS THAT MAKE UP LOS LAGOS ELECTRICAL SYSTEM.

\begin{tabular}{|c|c|c|c|}
\hline Types of Energy & $\begin{array}{c}\text { Cochamó } \\
{[\mathrm{MW}]}\end{array}$ & $\begin{array}{c}\text { Hornopirén } \\
{[\mathrm{MW}]}\end{array}$ & $\begin{array}{c}\text { Los Lagos } \\
\text { Electrical System } \\
{[\mathrm{MW}]}\end{array}$ \\
\hline Renewables & $\mathbf{0 , 0 0}$ & $\mathbf{0 , 7 7}$ & $\mathbf{0 , 7 7}$ \\
\hline Mini Hidraulyc Pass & 0,00 & 0,77 & 0,77 \\
\hline No Renewables & $\mathbf{3 , 0 0}$ & $\mathbf{3 , 7 5}$ & $\mathbf{6 , 7 5}$ \\
\hline Diesel Oil & 3,00 & 3,75 & 6,75 \\
\hline Total & $\mathbf{3 , 0 0}$ & $\mathbf{4 , 5 2}$ & $\mathbf{7 , 5 2}$ \\
\hline
\end{tabular}

the electricity market of the National Electrical System (SEN) of Chile and the Argentine Interconnection System (SADI).

The plant provides two countries that are not interconnected, so it has a $345[k V]$ transmission line, with which it connects to the SEN [14].

\section{G. Distributed Generation in Chile}

Chile is a country with great potential for the implementation of NCRE and in favor of promoting the efficient use of energy, in October 2014, Law 20,571 goes into effect, which grants the right to customers of distribution companies to generate your own energy, consume it and sell their surpluses. This right includes generation facilities based on renewable energy or efficient cogeneration, for example, photovoltaic, wind and hydraulic systems, with a maximum generation up to $100[\mathrm{~kW}$. This has allowed the installation of more than 4,000 generating systems, which as a whole have an installed generation capacity of more than $20[M W]$. This regulation has been recently modified by the publication of Law 21,118 in November 2018 in order to continue promoting the implementation of own generation systems, the maximum allowed generation value of $100[k W]$ has been modified to $300[k W]$. Expanding the maximum capacity allows commercial users and small industries to participate in the right granted by the legislation for self-generation, in addition this modification opens the possibility to the creation of community or joint ownership systems, where users can coordinate to install a single power generation system and take advantage of the benefits of the right granted by this law [15]. The implementation of distributed generation legislation initiates the way to the change of the unidirectional structure of the current Chilean electricity network.

\section{Future of the Chilean Electrical Grid}

Chile, with the creation of the Ministry of Energy in 2010 and later in 2014 with the Energy Agenda, adopted the commitment to create an efficient and cleaner energy matrix, so that the future of the Chilean electricity grid is oriented towards use of NCRE, and with the projected gaze towards the future, the energy policy Energy 2050 is born.

\section{A. Energy 2050: Energy Policy of Chile}

The Energy Policy proposes a vision of the energy sector by the year 2050 with the idea of generating a reliable, sustainable, inclusive and competitive sector, committing to move towards a more sustainable energy matrix.

In order to develop the 2050 energy vision, 4 fundamental pillars have been established, which are:

- Security and Supply Quality.

- Energy as a Development Engine.

- Compatibility with the Environment.

- Efficiency and Energy Education.

These 4 pillars are the basis for supporting the proposed measures and action plans [16].

The energy policy proposes 10 long-term goals for the year 2050 and medium-term goals for the year 2035 based on the 4 established pillars.

\section{B. Main Goals for the Year 2035}

The main goals for the year 2035 are detailed below.

- Interconnection of Chile with the other member countries of SINEA (Andean Electric Interconnection System), as well as with other countries in South America, especially with the MERCOSUR countries (Southern Common Market).

- The interruption of the electricity supply does not exceed 4 hours/year throughout the country, except when due to major force.

- All homes of vulnerable families have access to a continuous and quality electricity supply.

- Position Chile within the 5 OECD countries (Organization for Economic Cooperation and Development) with lower average prices of electricity supply, both residential and industrial.

- Achieve a generating matrix with at least $60 \%$ of electricity from renewable energy.

- Achieve a reduction of $30 \%$ of its greenhouse gas emissions by 2030 compared to 2007.

- All major industrial, mining and transport sector energy consumers should make efficient use of energy, implementing energy management systems and active implementation of energy efficiency improvements.

- All communities must have regulations, declaring forest biomass as solid fuel.

- All public transport vehicles tendered include energy efficiency criteria within the variables to be evaluated.

\section{Main Goals for the Year 2050}

The main goals for the year 2050 are detailed below.

- It is expected that the power shutdown will not exceed one hour/year in any part of Chile.

- The GHG (Greenhouse Gases) emissions from the energy sector do not exceed the limits established by science globally, reducing carbon emissions in energy generation.

- Ensure energy supply to the entire Chilean population. 
- Incorporation of regional planning and territorial planning instruments, incorporating the guidelines of the Chilean Energy Policy.

- Position Chile within the 3 OECD countries with lower average electricity supply prices, residential and industrial.

- Achieve a generating matrix with at least $70 \%$ of electricity from renewable energy.

- Decoupling the growth of energy consumption and the growth of gross domestic product.

- Implement $100 \%$ of new buildings with OECD standards for efficient construction, and intelligent energy control and management systems.

- Regulate the market so that $100 \%$ of the artifacts and equipment sold correspond to highly energy efficient equipment.

- To massify the energy culture at all levels of society, including producers, marketers, consumers and users.

\section{Characteristics of the Electrical Grid towards the year} 2050

The future Chilean electrical grid will be bidirectional with an active participation by consumers in the generation and distribution sector. It will also be an intelligent network grouping within a single management system the areas of protection coordination, control, instrumentation, measurement, quality and energy management, with the aim of achieving a measured and energy efficient use.

The intelligent electrical grid is a form of efficient electricity management that uses the development of computer engineering in order to optimize the production and distribution of electrical energy. For the future of Chile, in accordance with national energy policies and the incorporation of an energy generation matrix based on renewable energies, together with the mass generation of self-generation, it is expected to realize an electricity network with two-way energy flow and high participation of the citizens in the electricity generation sector.

The implementation of an intelligent electricity network will save energy and reduce its costs to meet the needs of consumers through bidirectional digital technology, causing electricity from suppliers to be sent to consumers in a controlled and efficient manner.

The implementation of Law 21,118 allows Chile to advance through the field of distributed generation, placing the generating plants very close to the loads, improving energy efficiency and significantly reducing losses resulting from transmission distances, considerably improving the reliability of the system.

In Fig. 2, the architecture of the future Chilean electricity network is presented, based on the distributed generation model with a bi-directional energy flow, where it is observed that the generated energy passes through a trunk transmission system towards the electrical sub-transmission to customers, where they can carry out their electric self-generation from various types of energy sources, mainly renewable, which re-

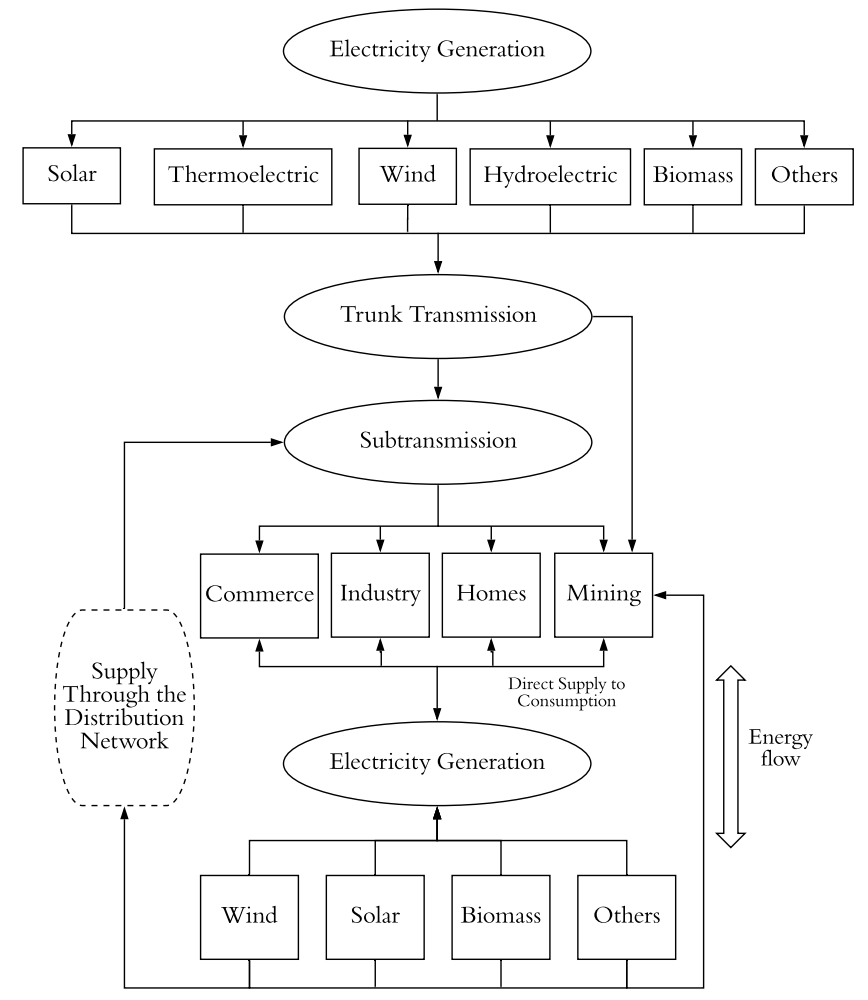

Fig. 2. General architecture of the future Chilean electricity network.

turn to the sub-transmission lines through the local distribution networks, forming this way a two way energy flow.

\section{E. Projects in Paths to the Future}

There are currently more than 500 projects in qualification processes, for a total of $35,809[M W]$ of which $80 \%$ correspond to renewable energy [17]. For the year 2019, 65 of these projects are expected to be put into operation, of which $90 \%$ of these are from renewable energy and more than 30 transmission initiatives.

Among the projects for 2019, Aurora, Cerro Dominador, Huatacondo, San Gabriel and Sarco stand out for being largescale projects based on NCRE, together they will have a power of $690[M W]$, with Cerro Dominador being the most expensive, with an approximate total investment of 1,147 million dollars.

Some of the most important generation projects for Chile are presented below.

\section{F. Cerro Dominador Project}

The Cerro Dominador solar complex located in the town of Santa Elena at $59.4[\mathrm{~km}]$ from the city of Calama, is the first solar concentration project in Latin America, once the project is finished, it will have an installed capacity of $210[M W]$ from totally clean generation, joining the Chilean electricity market with a combination of $100[M W]$ of photovoltaic origin and $110[M W]$ of solar concentration energy.

The solar concentration plant will have a storage capacity of 17.5 hours, which will guarantee continuous energy production 
24 hours a day, 365 days a year. In addition, this plant is located in an area that has one of the highest solar radiation rates in the world, being the first renewable energy plant that will produce base energy in Chile and is expected to be operational by 2020 [18].

\section{G. Espejo de Tarapacá Project - Valhalla}

Espejo de Tarapacá (EdT) is one of the most ambitious and innovative generation projects, located approximately 100 $[\mathrm{km}]$ south of Iquique, consists of a hydraulic pumping station of $300[M W]$, pumping water from sea towards the reservoirs located in a coastal farellón with $700[\mathrm{~m}]$ high, very close to the ocean. In its upper part it has natural concavities, which will be used for water storage. The use of these geographical conditions minimizes the environmental impact and the monetary cost of the project, which, adding the implementation of photovoltaic panels located in one of the areas with the highest solar radiation in the world, makes EdT an option for generating clean and abundant energy.

EdT is a revolutionary project in generation systems, however, it has gone through various financial complications, which has led to the idea of abandoning the idea of implementing this project. At the beginning of 2018 the UN (United Nations Organization) selected Espejo de Tarapacá to receive funding from the Green Fund of the organization of 500 million dollars. This made EdT the only large-scale energy project selected worldwide [19].

\section{CONCLUSION}

This paper has presented a review of the implementation of the current Chilean energy legislation, which allows the change of energy flow within its electrical system. The current situation of the electrical grid in Chile is contextualized, along with its most recent advances in infrastructure and most outstanding projects for the future.

Due to the change in legislation, Chile is currently evolving its orientation of the generating matrix, which opens the doors to new distributed generation systems and smart grids.

The interconnection of the SING and SIC systems has managed to interconnect Chile at $99 \%$, however, there is still $1 \%$ that does not receive the benefits of the interconnection.

The change in Chile's electricity generating matrix to a cleaner matrix will improve the life quality of Chilean, as well as the image of what this country represents to the world. Currently, Chile has all the opportunities to become an energy potency for both Latin America and the world.

\section{ACKNOWLEDGMENT}

This publication was made within the framework of the thematic task force on Energy-CUECH Research Network. The authors appreciate the financial support of the FONDECYT Regular Project 1160690.

\section{REFERENCES}

[1] G. de Chile. Generación Eléctrica en Chile. (2019). [Online]. Available: http://www.generadoras.cl

[2] M. de Energía. Agenda de Energía Un Desafío País, Progreso para Todos. (2014). [Online]. Available: http://www.sec.cl

[3] B. Finance. Emerging Markets Outlook 2018. (27 Noviembre, 2018). [Online]. Available: http://global-climatescope.org

[4] Electricidad. El Futuro de los Sistemas Eléctricos Medianos. (19 Diciembre, 2017). [Online]. Available: http://www.revistaei.cl

[5] CEEDES. Aprende cómo funciona el sistema eléctrico en Chile. (17 Febrero, 2015). [Online]. Available: http://ceedes.cl

[6] CNE. Se Concreta la Interconexión de los Sistemas Eléctricos SIC y SING con la Precencia de la Presidenta de la República. (21 Noviembre, 2017). [Online]. Available: https://www.cne.cl

[7] TEN. Proyecto Línea de Transmisión Mejillones-Cardones. (2017, Nov.). [Online]. Available: http://www.tenchile.cl

[8] CEN. Sistema Eléctrico Nacional. (2017). [Online]. Available: https://www2.coordinador.cl

[9] C. Jorquera. Primera Planta Geotérmica de America del Sur- Cerro Pabellón de 48 MW Inicia Operación. (3 Abril, 2017). [Online]. Available: http://www.piensageotermia.com

[10] Electricidad. Eléctrica de Aysén Logra que $81 \%$ de su Electricidad sea Renovable. (25 Junio, 2018). [Online]. Available: http://www.revistaei.cl

[11] Edelmag. Sistema de Magallanes. (Mayo, 2019). [Online]. Available: http://www.edelmag.cl

[12] U. de Chile. Sector Eléctrico Chileno. (20 Mayo, 2015). [Online]. Available: www.cec.uchile.cl

[13] M. de Energía. Ministra Jiménez Inaugura la Primera Planta de Generación Fotovoltaica en Isla de Pascua. (9 Noviembre, 2018). [Online]. Available: http://energia.gob.cl

[14] A. Gener. TERMOANDES S.A. (10 Octubre, 2018). [Online]. Available: http://www.guiachileenergia.cl

[15] C. Nacional. Ley 21.118. (9 Noviembre, 2018). [Online]. Available: https://www.leychile.cl/Navegar?idNorma $=1125560$

[16] M. de Energía. Energía 2050 Política Energética de Chile. (2015, Sept.). [Online]. Available: http://www.energia2050.cl

[17] Electricidad. 61\% de los Futuros Proyectos de Energías Renovables se Concentran en Ocho Comunas. (21 Noviembre, 2018). [Online]. Available: http://www.revistaei.cl

[18] E. G. E. Partners. Proyecto Cerro Dominador. (Mayo, 2019). [Online]. Available: https://cerrodominador.com

[19] Valhalla. Proyecto Espejo de Tarapacá. (Mayo, 2019). [Online]. Available: http://www.valhalla.cl 